\title{
Correction to: New host and distribution records of bat flies (Diptera: Streblidae, Nycteribiidae) on cave-dwelling bats from Bohol Island, Philippines
}

\author{
Ace Kevin S. Amarga ${ }^{1,2,3} \cdot$ Kendra L. Phelps $s^{4,5}$
}

Accepted: 12 August 2021 / Published online: 16 November 2021

(c) African Association of Insect Scientists 2021

\section{Correction to: International Journal of Tropical Insect Science https://doi.org/10.1007/s42690-021-00584-7}

In the above mentioned publication, the reference for Amarga et al. (2017) was erroneously removed during production. The original article has been corrected and the respective reference is also provided here.

\section{Reference}

Amarga AKS, Alviola P, Lit Jr IL, Yap S (2017) Checklist of ectoparasitic arthropods among cave-dwelling bats from Marinduque Island, Philippines. Check List 13(1):2029

The original article can be found online at https://doi.org/10.1007/ s42690-021-00584-7.

Ace Kevin S. Amarga

ace_amarga061@yahoo.com

1 Biodiversity Program, Taiwan International Graduate Program, Biodiversity Research Center, Academia Sinica, Nangang District, Taipei 11529, Taiwan

2 School of Life Science, National Taiwan Normal University- Gongguan Campus, Wenshan District, Taipei 11677, Taiwan

3 Royal Belgian Entomological Society, Rue Vautier 29, 1000 Brussels, Belgium

4 EcoHealth Alliance, New York City, NY 10018, USA

5 Southeast Asian Bat Conservation Research Unit, Lubbock, TX 79409, USA
Publisher's Note Springer Nature remains neutral with regard to jurisdictional claims in published maps and institutional affiliations. 